\title{
STABILITY ANALYSIS OF THE CLIMATE-VEGETATION SYSTEM IN THE NORTHERN HIGH LATITUDES
}

\author{
VICTOR BROVKIN $^{1}$, SAMUEL LEVIS ${ }^{2}$, MARIE-FRANCE LOUTRE ${ }^{3}$, \\ MICHEL CRUCIFIX ${ }^{3}$, MARTIN CLAUSSEN ${ }^{1,4}$, ANDREY GANOPOLSKI ${ }^{1}$, \\ CLAUDIA KUBATZKI ${ }^{1}$ and VLADIMIR PETOUKHOV ${ }^{1}$ \\ ${ }^{1}$ Potsdam-Institut für Klimafolgenforschung, P.O. Box 601203, 14412 Potsdam, Germany \\ ${ }^{2}$ National Center for Atmospheric Research, P.O. Box 3000, Boulder, CO 80307-3000, U.S.A. \\ ${ }^{3}$ Institut d'Astronomie et de Géophysique G. Lemaître, Université catholique de Louvain, \\ 2 Chemin du Cyclotron, B-1348, Louvain-la-Neuve, Belgium \\ ${ }^{4}$ Institut für Meteorologie, Freie Universität Berlin, Germany
}

\begin{abstract}
The stability of the climate-vegetation system in the northern high latitudes is analysed with three climate system models of different complexity: A comprehensive 3-dimensional model of the climate system, GENESIS-IBIS, and two Earth system models of intermediate complexity (EMICs), CLIMBER-2 and MoBidiC. The biogeophysical feedback in the latitudinal belt $60-70^{\circ} \mathrm{N}$, although positive, is not strong enough to support multiple steady states: A unique equilibrium in the climate-vegetation system is simulated by all the models on a zonal scale for present-day climate and doubled $\mathrm{CO}_{2}$ climate. EMIC simulations with decreased insolation also reveal a unique steady state. However, the climate sensitivity to tree cover, $\Delta T_{F}$, exhibits non-linear behaviour within the models. For GENESIS-IBIS and CLIMBER-2, $\Delta T_{F}$ is lower for doubled $\mathrm{CO}_{2}$ climate than for present-day climate due to a shorter snow season and increased relative significance of the hydrological effect of forest cover. For the EMICs, $\Delta T_{F}$ is higher for low tree fraction than for high tree fraction, mainly due to a time shift in spring snow melt in response to changes in tree cover. The climate sensitivity to tree cover is reduced when thermohaline circulation feedbacks are accounted for in the EMIC simulations. Simpler parameterizations of oceanic processes have opposite effects on $\Delta T_{F}: \Delta T_{F}$ is lower in simulations with fixed SSTs and higher in simulations with mixed layer oceans. Experiments with transient $\mathrm{CO}_{2}$ forcing show climate and vegetation not in equilibrium in the northern high latitudes at the end of the 20th century. The delayed response of vegetation and accelerated global warming lead to rather abrupt changes in northern vegetation cover in the first half of the 21 st century, when vegetation cover changes at double the present day rate.
\end{abstract}

\section{Introduction}

The global distribution of vegetation is, to a first approximation, controlled by climate (Woodward, 1987). Although summer water stress is possible in the continental interior of the northern high latitudes, the key limiting factor for tree growth in the region is a heat (or temperature) factor, which can be expressed in terms of a sum of degree-days (sum of surface air temperature for days when temperature is above some threshold). In this form the heat requirement is usually used as a factor which limits forest propagation northwards within terrestrial vegetation models (Prentice et al., 1992; Cramer et al., 2001). At the same time, the physical 


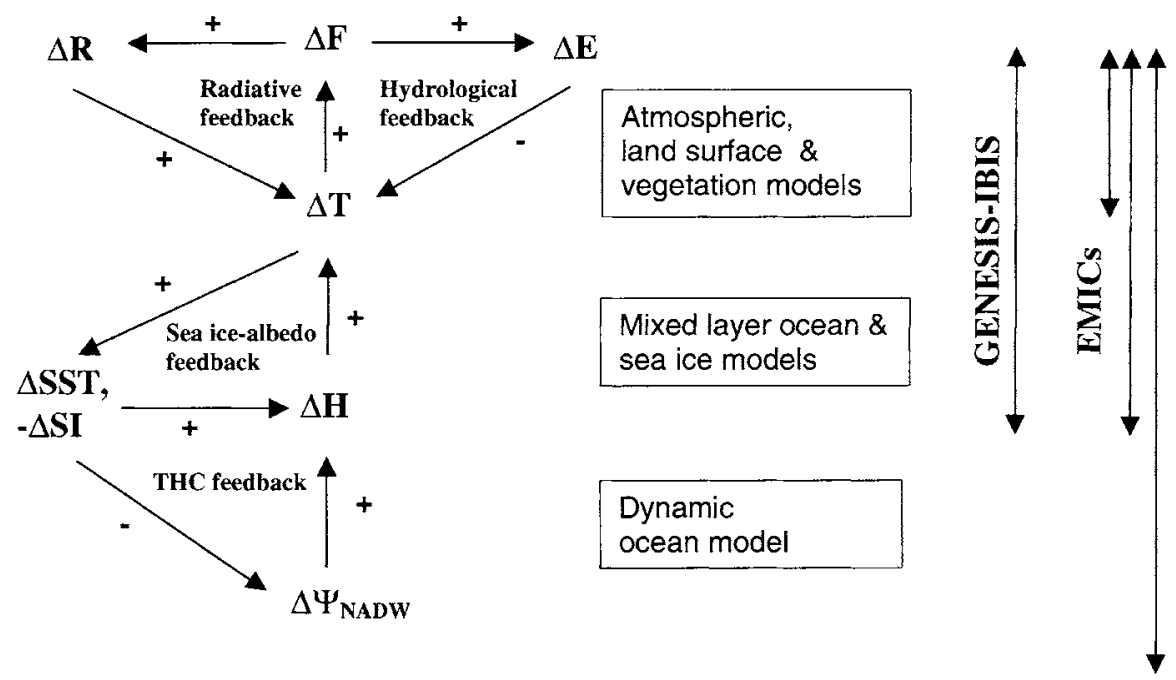

Figure 1. Sketch of climate-vegetation interactions in the northern high latitudes and hierarchy of model compartments in the feedback analysis. The arrows on the left indicate relations between variables, including amplification (+) or dampening (-) of the original change $\Delta$. F refers to tree fraction; $\mathrm{T}$, to surface air temperature; $\mathrm{R}$, to the net radiation at the surface; E, to evapotranspiration; SST, to sea surface temperature; SI, to sea ice; $\mathrm{H}$, to heat fluxes out of the ocean and into the atmosphere; $\Psi_{\mathrm{NADW}}$, to the intensity of the thermohaline circulation. The boxes in the middle indicate model compartments necessary to investigate feedbacks shown on the left. The arrows on the right refer to the types of models used in the paper.

characteristics of trees (e.g., height, albedo, roughness, stomatal resistance) differ from those of grass or moss or bare ground. Such differences, in turn, explain the effect of land cover change on climate.

Forests, even deciduous ones, significantly reduce the albedo of snow covered surfaces (Betts and Ball, 1997; Ni and Woodcock, 2000). This is the basis for the radiative feedback between forest and surface air temperature: increased tree fraction $\rightarrow$ decreased surface albedo during snow season $\rightarrow$ increased air temperature and earlier snow melt $\rightarrow$ longer and warmer growing season $\rightarrow$ increased tree fraction. This feedback is positive, i.e., it enhances the system response to the original external forcing (Figure 1). This feedback is dampened during the growing season, when trees have a denser, more productive canopy than herbaceous plants and moss, and, therefore, transpire more water. This suggests a greater latent heat flux and a cooling of surface air in forests as compared to tundra (Pielke et al., 1998). This hydrological feedback, although negative (Figure 1), is secondary to the radiative feedback on the annual average.

The radiative feedback was first explored in simulations with multilayer energy balance models (Otterman et al., 1984; Harvey, 1988). These studies found significant hemispheric cooling in the absence of boreal forests masking the snow. After land surface schemes in GCMs began to consider different vegetation types 
explicitly, see, e.g., Dickinson et al. (1986), the impact of boreal vegetation on climate became a model benchmark. Sensitivity simulations with GCMs done by Bonan et al. (1992), Thomas and Rowntree (1992), Chalita and Le Treut (1994), and Douville and Royer (1996) confirmed the cooling effect of boreal deforestation. Their analysis was primarily focused on radiative effects. The subsequent studies by Bonan et al. (1995), Betts (1999), Kleidon et al. (2000), and Heck et al. (2001) revealed that during the summer the hydrological effect of deforestation is comparable to the radiative effect.

Most of these simulations were done with sea surface temperatures (SSTs) and sea ice prescribed from present-day observations. However, the radiative and hydrological feedbacks depend on the oceanic response. Particularly, the original increase in forest area can be amplified by the sea ice-albedo feedback: increased surface air temperature $\rightarrow$ increased SSTs and decreased sea ice area $\rightarrow$ decreased surface albedo $\rightarrow$ increased surface air temperature (Figure 1). The significance of the sea ice-albedo feedback was first shown in boreal deforestation simulations done by Harvey (1988) and Bonan et al. (1992). They used mixed layer ocean models and thermodynamic sea ice models which are computationally inexpensive. However, SST and sea ice changes, especially in the region of Atlantic deep water formation, are dampened by a negative feedback due to the thermohaline circulation (THC): increased SSTs $\rightarrow$ lower density of the surface water $\rightarrow$ decreased thermohaline overturning and northward oceanic heat transport $\rightarrow$ reduced SSTs (Figure 1). This and other feedbacks associated with changes in the oceanic circulation (see, e.g., Rahmstorf et al., 1996) can be generated only by dynamic ocean models which simulate ocean circulation. The time scale of deep ocean dynamics is several hundred years, so the long-term effect of boreal deforestation on the THC has not been explored with coupled atmosphere-ocean GCMs. Computationally efficient climate models of intermediate complexity, EMICs, play a crucial role in this respect (McGuffie and Henderson-Sellers, 2001; Claussen et al., 2002).

Paleosimulations for the mid-Holocene (Foley et al., 1994; Claussen and Gayler, 1997; Ganopolski et al., 1998; Hewitt and Mitchell, 1998; Texier et al., 1997; Crucifix et al., 2002) the last glacial maximum (Kubatzki and Claussen, 1998; Levis et al., 1999b), last interglacial time slices (Gallimore and Kutzbach, 1996; de Noblet et al., 1996; Kubatzki et al., 2000), and the last 1,000 years (Brovkin et al., 1999) highlighted the boreal forest-climate feedback as an amplifier of externally driven climate change. This feedback was also shown in doubled $\mathrm{CO}_{2}$ simulations (Levis et al., 1999c; Ganopolski et al., 2001; Bergengren et al., 2001) where a northward shift of the boreal treeline influenced the regional climate (Pielke and Vidale, 1995; Henderson-Sellers and McGuffie, 1995).

Non-linearities in biochemical and biophysical processes can result in various steady states for ecosystems on a local scale (Scheffer et al., 2001). Zerodimensional models of climate-vegetation interactions on local (Bogatyrev, 1991) and global scales (Svirezhev and von Bloh, 1996) pointed to the possibility of multiple equilibria due to climate-vegetation interactions. However, experiments 
with geographically explicit models of the global climate system did not reveal multiple steady states in the northern high latitudes. The easiest way to detect multiple steady solutions is to allow climate-vegetation models to evolve freely from different initial vegetation states, for example from $100 \%$ forest cover or from 100\% tundra cover. Claussen (1994) and Kubatzki and Claussen (1998) in such experiments with the coupled ECHAM-BIOME model obtained a unique steady state for present-day and last glacial maximum time slices, respectively. Levis et al. (1999a) in a similar experiment with the GENESIS-IBIS model for present-day climate did not find multiple steady states in the Asian boreal region.

In this paper, we explore the stability of the climate-vegetation system in the northern high latitudes under changes in external forcing. We use three coupled atmosphere-ocean-vegetation models of different complexity: GENESIS-IBIS, CLIMBER-2, and MoBidiC. Although model design differs, the three models show similar sensitivity to interactive changes in vegetation cover under a doubled $\mathrm{CO}_{2}$ forcing (Table I). With the two EMICs, we investigate the role of radiative, hydrological and oceanic feedbacks in more detail than with GENESIS-IBIS (Figure 1) and perform long-term transient simulations to explore the difference between transient and equilibrium responses. We interpret the results of the numerical models in terms of a simple conceptual model and perform a phase plane analysis (Brovkin et al., 1998; Levis et al., 1999a). This qualitative geometrical analysis of stability is complementary to the factor analysis of feedbacks (Schlesinger, 1985; Stein and Alpert, 1993). The analysis is limited to biogeophysical feedbacks, i.e., the negative feedback of the boreal forest on the carbon cycle is not considered. Recent investigations agree that in the boreal region the biogeophysical feedbacks outweigh the biogeochemical ones (Betts, 2000; Claussen et al., 2001). Our analysis is limited by land surface and vegetation models which do not simulate fires or permafrost, processes which influence vegetation dynamics in the boreal region (Fosberg et al., 1999; Tyrtikov, 1995). These limitations do not degrade the equilibrium analysis significantly because stationary distributions of permafrost (Gavrilova, 1981) and boreal forests (Prentice et al., 1992) are well correlated with surface air temperature which is accounted for in the models. Also, the coarse resolution employed by the EMICs can undermine the significance of remote effects (Chase et al., 2000) and short-term oscillations in the Arctic climate system (Baldwin and Dunkerton, 2001). This makes the comparison of the two EMICs with GENESIS-IBIS very important. We use decadal averaging of the results to smooth out short-term variability.

\section{Conceptual Model of Climate-Vegetation Interaction in the Northern High Latitudes}

The conceptual model assumes that, in the northern high latitudes, with fixed external climate parameters $E$ (e.g., atmospheric $\mathrm{CO}_{2}$ concentration, insolation), the 
Table I

Model summary

\begin{tabular}{|c|c|c|c|}
\hline Model feature & GENESIS-IBIS & CLIMBER-2 & MoBidiC \\
\hline Resolution $\left({ }^{\circ}\right.$ lat $\times{ }^{\circ}$ lon $)$ & $4.5 \times 7.5$ & $10 \times 51$ & $2.5 \times 33$ \\
\hline Atmospheric model & GCM & $\operatorname{SDM}^{\mathrm{a}}$ & $\mathrm{QGM}^{\mathrm{b}}$ \\
\hline \multirow[t]{2}{*}{ Ocean model } & \multirow[t]{2}{*}{$M L^{c}$} & (1) $2-\mathrm{D}(\varphi, z)^{\mathrm{d}}$ & (1) $2-\mathrm{D}(\varphi, z)^{\mathrm{d}}$ \\
\hline & & (2) fixed SSTs & (2) $\mathrm{ML}$ \\
\hline Vegetation model & DGVM & DGVM & DGVM \\
\hline - number of PFTs & 9 & 2 & 2 \\
\hline Analysed zonal belt & $58.5-72^{\circ} \mathrm{N}$ & $60-70^{\circ} \mathrm{N}$ & $60-70^{\circ} \mathrm{N}$ \\
\hline \multicolumn{4}{|l|}{ Simulated periods, yr: } \\
\hline$-(\mathrm{S}),{ }^{\mathrm{e}}(0),(\mathrm{C})$ states & 50 & 2,000 & 5,000 \\
\hline$-F^{*}(T, E)$ curves & 50 & 10,000 & 10,000 \\
\hline$-T^{*}(F, E)$ curves & 50 & 11,000 & 5,500 \\
\hline- transient $\mathrm{CO}_{2}$ run & - & 2,200 & 2,200 \\
\hline \multicolumn{4}{|l|}{$2 \times \mathrm{CO}_{2}$ sensitivity: $\mathrm{f}$} \\
\hline - fixed vegetation $\mathrm{g}$ & 2.5 & 2.5 & 2.1 \\
\hline - interactive vegetation $\mathrm{h}$ & 2.6 & 2.6 & 2.2 \\
\hline
\end{tabular}

a Statistical-dynamical model.

b Quasi-geostrophic model.

c Mixed layer ocean model.

d Zonally-averaged 3-basin ocean model.

e EMICs only.

${ }^{\mathrm{f}}$ Difference in global mean annual temperature $\left({ }^{\circ} \mathrm{C}\right)$ between $2 \times \mathrm{CO}_{2}$ and $1 \times \mathrm{CO}_{2}$ simulations.

$\mathrm{g}$ Vegetation cover is prescribed from $1 \times \mathrm{CO}_{2}$ simulation.

$\mathrm{h}$ Vegetation cover interacts with $2 \times \mathrm{CO}_{2}$ climate.

equilibrium surface air temperature $T$ over a sufficiently large land area depends on the average tree fraction $F$ (and not on other vegetation characteristics), while the average tree fraction $F$ depends on the surface air temperature $T$ (and not on other climate characteristics). The surface air temperature $T$ in our analysis is expressed in terms of growing degree-days above $0^{\circ} \mathrm{C}$ (GDD0). By tree fraction $F$ we understand a fraction of land covered by a tree canopy; during the snow season, trees are assumed to be taller than snow depth (Chapin et al., 1996). When vegetation and climate are in equilibrium, the values of $F$ and $T$ solve the following system of equations:

$$
\begin{aligned}
& F=F^{*}(T, E), \\
& T=T^{*}(F, E),
\end{aligned}
$$

where $F^{*}(T, E)$ is an equilibrium dependence of vegetation on climate, or, in mathematical terms, an equilibrium manifold for the variable $F$. This manifold is 


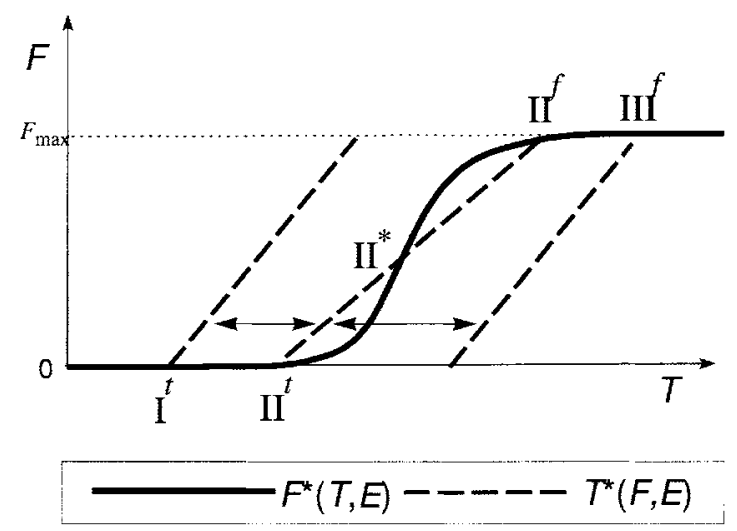

Figure 2. Schematic of the conceptual model. The solid curve represents the dependence of equilibrium tree fraction on air temperature in terms of degree-days. The dashed line represents the linear model of degree-days as a function of tree fraction. Cases I and III correspond to one equilibrium solution, 'tundra' I ${ }^{t}$ and "taiga" III ${ }^{f}$, respectively. Hypothetical case II corresponds to the stable 'tundra' II $^{t}$ and 'taiga' II $^{f}$ equilibria as well as the unstable II $^{*}$ solution. Arrows show the transition of $T^{*}(F, E)$ under the evolution of an external parameter $E . F_{\max }$ is the potential maximum tree fraction (close to 1$)$.

obtained from the vegetation model assuming that $T$ varies independently and not in response to tree fraction changes. Similarly, $T^{*}(F, E)$ is an equilibrium dependence of the climate on vegetation which is obtained from the atmosphere/ocean model assuming that $F$ varies independently and not in response to temperature changes. The climate system components outside the area of consideration (e.g., SST, sea ice) are assumed to be in equilibrium with $F$ and $E$. In the following, we seek a parameterization for the dependencies $F^{*}$ and $T^{*}$ based on results from our simulations.

Theoretically speaking, the dependence of $F=F^{*}(T, E)$ in cold regions obeys the following general rule: $F$ is near zero up to some critical threshold $T_{c r}$, then it grows fast, and approaches a saturation level (Figure 2). A further increase in temperature can lead to a decrease in the tree fraction because of water or heat stress, but we analyse here the part of the phase plane before such a decrease.

Temperature, in turn, increases monotonically, and for simplicity we assume linearly, with an increase in $F$ (Figure 2). Of importance upon comparing between our models is the climate sensitivity to vegetation change, which can be quantified by the average slope of curve $T^{*}(F, E)$ expressed in terms of degree-days: $\Delta T_{F}(E)=T^{*}(1, E)-T^{*}(0, E)$.

The points of intersection of the curves $F^{*}(T, E)$ and $T^{*}(F, E)$ in Figure 2 represent the equilibria of the climate-vegetation system. In the general case, the two curves intersect at either one or three points. The case of one intersection corresponds to one stable equilibrium in the climate-vegetation system. It could be a tundra state (case I) or a forest state (case III). Case II shows three solutions, one of which $\left(\mathrm{II}^{*}\right)$ is unstable and separates the domains of attraction of the stable 
equilibria. The nongeneral, or degenerate, case of two intersection points between curves $F^{*}(T, E)$ and $T^{*}(F, E)$ corresponds to a saddle-node bifurcation.

From an analysis of $F^{*}$ and $T^{*}$ as derived from our simulations, we may easily conclude whether the simulated feedbacks between climate and vegetation can result in multiple steady states. Under a changing external forcing $E$, the equilibrium manifold position will move to reflect a change in feedback strength.

Equations (1) and (2) are equilibrium solutions of a dynamical system which describes the long-term dynamics of the northern high-latitude climate system. Under changed external forcing $E$, this dynamical system evolves towards a new equilibrium with a time scale determined by the response time of the slowest system component. Results of the time scale analysis under transient $\mathrm{CO}_{2}$ forcing are presented in Section 4.3.

\section{Interpretation of the GENESIS-IBIS Results}

Foley et al. (1998) incorporated the IBIS biosphere model within the GENESIS AGCM (version 2) (Thompson and Pollard, 1997). In the coupled model, GENESIS, a three-dimensional AGCM, simulates the physics and general circulation of the atmosphere. It includes a 50-m slab-ocean model and a sea ice model. IBIS simulates vegetation processes (Table I). This model configuration allows for the simulation of the radiative and hydrological feedbacks, as well as their amplification through the sea ice-albedo feedback discussed in Section 1 (Figure 1). Here we interpret the results of the GENESIS-IBIS model in terms of Equations (1) and (2). We analyse present-day results (Levis et al., 1999a) and results for doubled atmospheric $\mathrm{CO}_{2}$ conditions (Levis et al., 1999c).

For present-day climate, an analysis of multiple equilibria on a phase plane was done by Levis et al. (1999a) on a regional scale. Here we use different units for vegetation (tree fraction instead of leaf area index) and zonal averaging over land $\left(58.5-72^{\circ} \mathrm{N}\right)$ in order to compare the sensitivity of GENESIS-IBIS to that of the two EMICs. In agreement with findings on a regional scale, there is a unique equilibrium for the modern climate simulated by GENESIS-IBIS on a zonal scale. The straight line $T^{*}(F, 0)$ ( 0 is for present-day) and curve $F^{*}(T, 0)$ (not shown) intersect at one point with approximate coordinates $(1080,0.4) . T^{*}(F, 0)$ (Figure 3a) has $\Delta T_{F}=410$ degree-days.

The doubled $\mathrm{CO}_{2}$ experiment (referred to as RPV in Levis et al., 1999c) was initialized from present-day conditions shown by point 1 in Figure 3a. In IBIS, plant productivity depends on the concentration of atmospheric $\mathrm{CO}_{2}$, so the curve $F^{*}(T, E)$ is a function of atmospheric $\mathrm{CO}_{2}$. Particularly, $F^{*}(T, C) \geq$ $F^{*}(T, 0)$, where $C$ represents doubled $\mathrm{CO}_{2}$ conditions. The procedure used to obtain $F^{*}(T, C)$ is described for the present-day case in Levis et al., 1999a. $F^{*}(T, C)$ in the form of a polynomial fit is shown in Figure 3a. For present-day GDD0, 
(a)

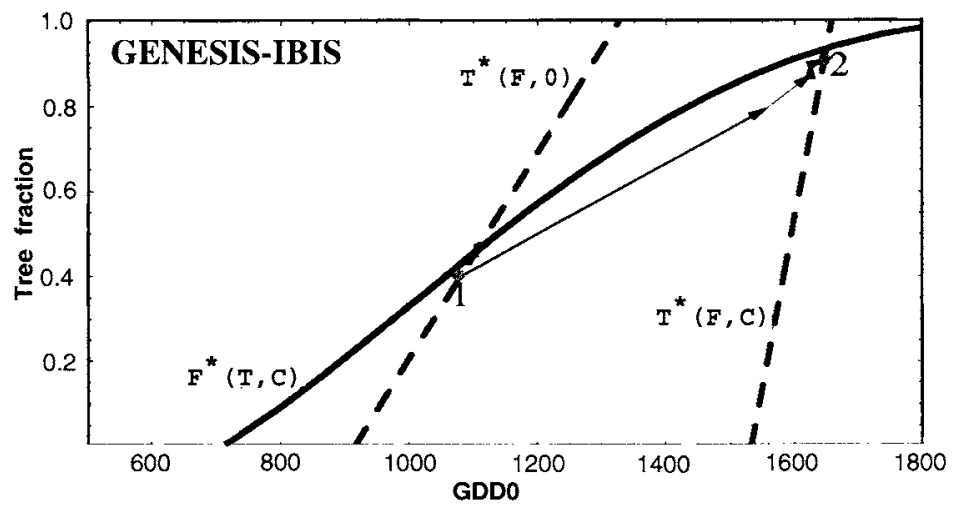

(b)

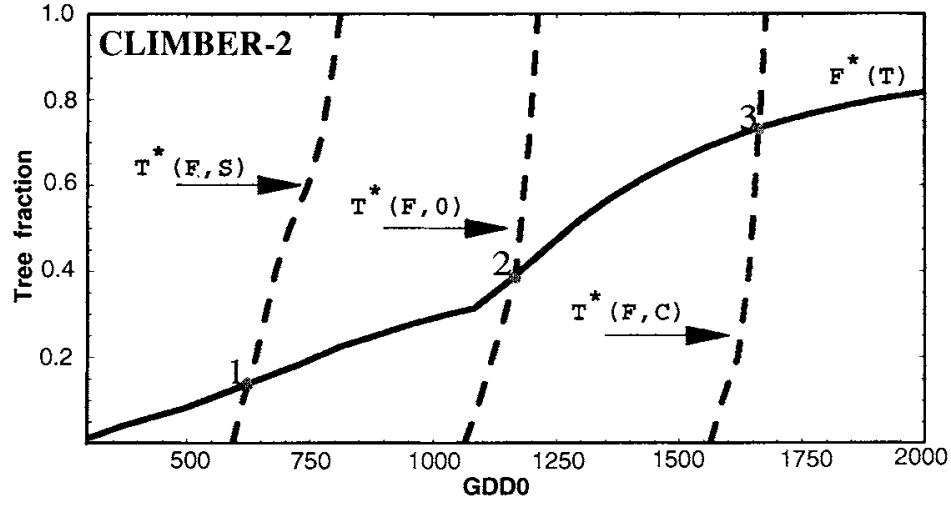

(c)

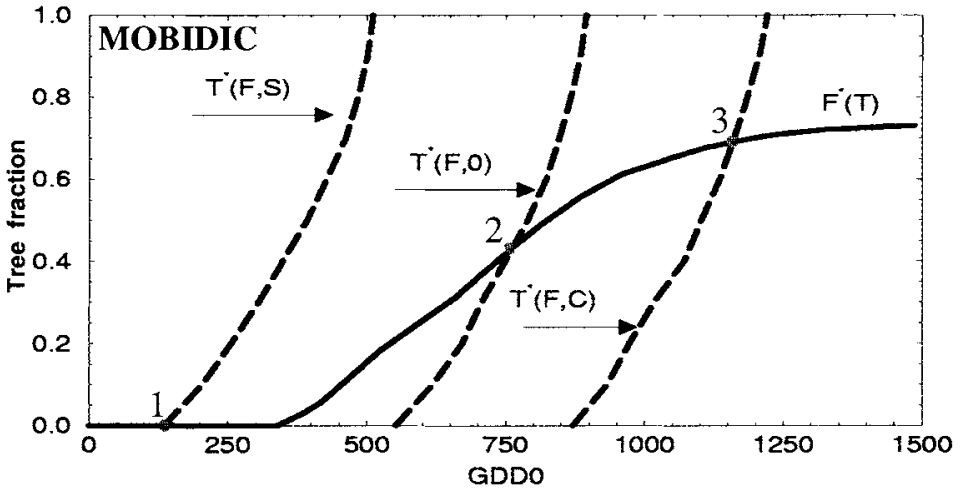

Figure 3. Interpretation of model results in terms of the conceptual model. (a) GENESIS-IBIS; Point 1 is the initial state and point 2 is the final state in the doubled $\mathrm{CO}_{2}$ experiment, arrows show the system dynamics in terms of decadal averages. (b) CLIMBER-2, (c) MoBidiC; points 1, 2, and 3 are steady states in present-day $(0)$, doubled $\mathrm{CO}_{2}(\mathrm{C})$, and decreased insolation $(\mathrm{S})$ simulations, respectively. The solid curve represents $F^{*}(T)$, dashed lines are for $T^{*}(F, E)$. 
$F^{*}(T, C)$ and $F^{*}(T, 0)$ are very similar, so point 1 is situated near $F^{*}(T, C)$ in Figure 3 a.

The actual system dynamics in simulation (RPV) (Levis et al., 1999c) are shown by arrows in Figure 3a, where the averaging period for $F, T$ is 10 years. The system state after 50 years of climate response is shown by point 2 with co-ordinates (1650, $0.9)$; it is situated very close to the curve $F^{*}(T, C)$. This fact and the slowdown of dynamics in the vicinity of point 2 suggest that the system is close to the new equilibrium under the new $\mathrm{CO}_{2}$ boundary condition.

To obtain curve $T^{*}(F, C)$, the results of another 20-year simulation (referred to as $R$ in Levis et al. (1999c)) are used. In this simulation, vegetation cover was fixed to its present-day extent, while climate evolved freely to a new equilibrium under double atmospheric $\mathrm{CO}_{2}$. On a phase plane, this equilibrium with co-ordinates $(1590,0.45)$ corresponds to a crossing point of two curves, $T^{*}(F, C)$ and $F^{*}(T, 0)$. The straight line passing through this point and point 2 , to a first approximation, is the $T^{*}(F, C)$ curve (see Figure $3 \mathrm{~b}$ ). The sensitivity $\Delta T_{F}$ is about 130 degreedays, considerably lower than the sensitivity for present-day climate. The curves $T^{*}(F, C)$ and $F^{*}(T, C)$ intersect at one point. Consequently, the model has a unique steady state under doubled $\mathrm{CO}_{2}$ climate. This state consists of both denser forest cover and warmer climate conditions than simulated for the same region at present-day.

\section{Experiments with EMICs}

We have performed a set of experiments with two EMICs, CLIMBER-2 (Petoukhov et al., 2000; Ganopolski et al., 2001) and MoBidiC (Crucifix et al., 2002). For the simulations presented here, MoBidiC was interactively coupled to the vegetation module of CLIMBER-2, VECODE. With respect to the global distribution of tree cover and the dynamics of the northern treeline under transient climatic and $\mathrm{CO}_{2}$ forcing, VECODE shows similar performance to other dynamic global vegetation models including IBIS (Cramer et al., 2001).

For the stability analysis, we zonally average our model results over land points in the zonal belt $60-70^{\circ} \mathrm{N}$. In VECODE, equilibrium tree fraction $F^{*}$ does not depend on atmospheric $\mathrm{CO}_{2}$ concentration, so $F^{*}(T, E)=F^{*}(T)$. Although in every model grid cell $F^{*}(T)$ is non-linear, the zonally averaged $F^{*}(T)$ shown in Figures 3b,c is rather linear. In order to analyse the position of curve $T^{*}(F)$ for different climatic conditions, we use the fully interactive EMICs to simulate present-day climate (0), a warm doubled $\mathrm{CO}_{2}$ climate (C), and a cold climate with $2 \%$ less total solar radiation than today (S). These steady states are then used as initial conditions for simulations with tree fraction prescribed uniformly over the studied area at levels from 0 to 1 by a step of 0.1 (see Table I for the time span of the simulations). The grass fraction in the study area and all vegetation everywhere else evolves freely towards a new equilibrium with climate. The results of these 
Table II

Simulated climate sensitivity to forest cover, $\Delta T_{F}$, for different ocean configurations

\begin{tabular}{llll}
\hline Simulation & Fixed SSTs & $\begin{array}{l}\text { Mixed layer } \\
\text { ocean }\end{array}$ & $\begin{array}{l}\text { Dynamic } \\
\text { ocean }\end{array}$ \\
\hline$-2 \%$ insolation (S) & $170^{\mathrm{a}}$ & $520^{\mathrm{b}}$ & $220,{ }^{\mathrm{a}} 375^{\mathrm{b}}$ \\
Present day (0) & $85^{\mathrm{a}}$ & $550,{ }^{\mathrm{b}} 410^{\mathrm{c}}$ & $150,{ }^{\mathrm{a}} 345^{\mathrm{b}}$ \\
$2 \times \mathrm{CO}_{2}(\mathrm{C})$ & $45^{\mathrm{a}}$ & $440,{ }^{\mathrm{b}} 130^{\mathrm{c}}$ & $120,{ }^{\mathrm{a}} 350^{\mathrm{b}}$ \\
\hline${ }^{\mathrm{a}}$ CLIMBER. & & & \\
b MoBidiC. & & & \\
c GENESIS-IBIS. & & & \\
\end{tabular}

experiments are averaged over the last 20 years of each simulation (Figures 3b,c and Table II).

In general, the sensitivity of the climate system to changes in forest cover, $\Delta T_{F}$, is lower for the warm climate than for the cold one. In CLIMBER-2, it is 220 degree-days for the cold climate, 150 degree-days for present-day climate, and 120 degree-days for the doubled $\mathrm{CO}_{2}$ climate. $\Delta T_{F}$ decreases with increasing temperature due to several reasons. First, the warmer the climate, the earlier the snow melt. Because of pronounced seasonal changes in the incoming radiation in the region, the earlier the snow melt the smaller changes in absorbed radiation due to the presence of forest. As a result, radiative effect of forest during the spring decreases with increasing temperature. Second, in warmer climate the period of vegetation growth, then forest transpires more water than grassland and cools the surface air, is longer. Therefore, the hydrological effect of forest (negative feedback) increases with increasing temperature. This leads to a further reduction in $\Delta T_{F}$.

The changes in radiative and hydrological effects of forest are also pronounced in case of increasing tree fraction under the same external forcing. These changes explain non-linear response of temperature to the changes in the tree fraction, see curves $T^{*}(F, E)$ in Figures 3b,c. The higher the tree fraction, the earlier the snow melt, the weaker the radiative effect and the stronger the hydrological effect (see discussion in Section 4.1). Therefore, the climate sensitivity is higher for low values of tree fraction than for high values of tree fraction.

As with CLIMBER-2, MoBidiC exhibits a unique steady state (see Figure 3c) in each of the simulated climates. The low GDD0 at present-day equilibrium, results from a slight cold bias of the model in the high latitudes. The climate sensitivity $\Delta T_{F}$ is 375,345 , and 350 for $(\mathrm{S}),(0)$, and (C) respectively. $\Delta T_{F}$ is higher than in CLIMBER-2, due to the absence of a hydrological feedback and the presence of the cold bias in the northern high latitudes in MoBidiC. However, as in CLIMBER2 , and due to the same processes, these results indicate higher climate sensitivity to 
forest cover for low tree fractions than for high ones. Our result is independent from the finding by $\mathrm{Ni}$ and Woodcock (2000) that, in the presence of snow, reducing low tree fractions gives greater increase in albedo than reducing high tree fractions. If such a mechanism were incorporated in the land surface schemes of EMICs, it would amplify the feedback for low tree fractions.

The sensitivity of CLIMBER-2 to its albedo parameterization was also explored. We prescribed snow albedo to the maximum value allowed by the land surface scheme ( 0.6 and 0.9 for visible and near-infrared wavelengths, respectively), and tree albedo to the minimum possible value ( 0.05 and 0.23 for the same radiation bands). In response, present-day climate becomes warmer and the sensitivity $\Delta T_{F}$ increases from 150 to 500 degree-days at equilibrium. Initializing this system with $F=0$ and $F=1$ and allowing vegetation to evolve freely, we find that the model converges to the one solution with $F \sim 0.4$. The model shows no propensity for multiple steady states in the region.

\subsection{SEASONALITY OF RADIATIVE AND HYDROLOGICAL EFFECTS}

With CLIMBER-2, we explore the seasonality of the temperature sensitivity to forest fraction, shown here as the temperature difference at equilibrium between two present-day simulations, one with $F=1$ and the other with $F=0$ in the belt 60 $70^{\circ} \mathrm{N}$ (Figure 4). The strongest response on the annual average occurs in the high northern latitudes where temperature increases by $1-2{ }^{\circ} \mathrm{C}$ (Figure $4 \mathrm{a}$ ). Atmosphere and ocean circulations spread the warming globally $\left(0.3^{\circ} \mathrm{C}\right)$. The seasonal response differs from the annual response due to changes in the relative significance of the radiative and the hydrological feedbacks. In winter, changes in albedo barely affect climate in the high northern latitudes due to very little incoming radiation. At that time, oceanic feedbacks result in a warming (not shown) similar in magnitude to the annual average. The hydrological effect of forest is also absent in winter. In May and June, when there is still snow on the ground, the radiative effect is most significant and the warming over land in the zone $60-70^{\circ} \mathrm{N}$ reaches $2-4{ }^{\circ} \mathrm{C}$ (Figure 4b). In July and August, the albedo difference between forest and tundra is small (less than 0.1) and the warming is much less pronounced than in spring. In contrast, the hydrological effect is stronger, resulting in relative summer cooling over the study area (Figure 4c). Still, the overall zonal and global effect of $F=1$ versus $F=0$ is a warming enhanced by increased SSTs and atmospheric water vapour.

\subsection{OCEANIC FEEDBACKS}

To assess the importance of oceanic feedbacks in CLIMBER-2, we repeat experiments (S), (0), (C) with equilibrium SSTs and sea-ice prescribed from the equivalent fully interactive simulations presented in Section 4 . The climate sensitivity $\Delta T_{F}$ is equal to 170,85 , and 45 degree-days for $(\mathrm{S}),(0)$ and $(\mathrm{C})$, respectively (Table II). The sensitivity of the model with fixed SSTs and sea ice is significantly 

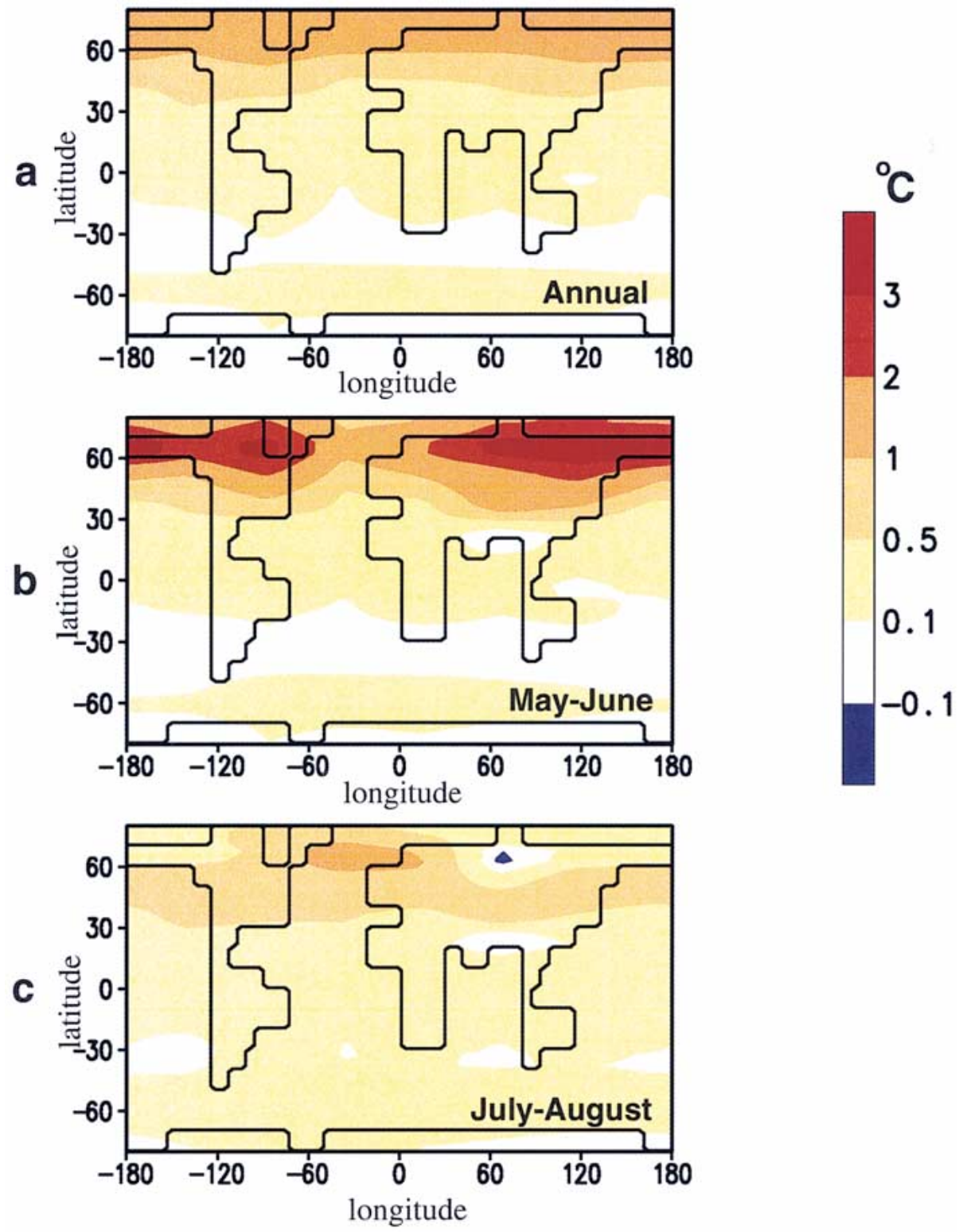

Figure 4. Maps of differences in surface air temperature between CLIMBER-2 simulations with forested $(F=1)$ and unforested $(F=0)$ land between $60-70^{\circ} \mathrm{N}$. (a) Annual average; (b) spring (May-June); (c) summer (July-August). 
lower than in the model with the dynamic ocean, especially for the doubled $\mathrm{CO}_{2}$ climate. The overall effect of the interactive ocean feedbacks, including sea icealbedo and thermohaline circulation feedbacks, is a significant amplification of the radiative and hydrological feedbacks induced by changes in forest cover.

In contrast, the mixed-layer configuration of MoBidiC (Gaspar, 1988) exhibits considerably higher sensitivity to change in the forest cover than the dynamic ocean model (Table II). The major difference between the two ocean configurations is an absence of the THC feedback in the mixed layer ocean. Simulation with dynamic ocean reveals a small decrease in the intensity of the thermohaline circulation in the Northern Atlantic (NADW) with increasing temperature, but the direct effect of changes in NADW on the heat fluxes is rather small in comparison with indirect effect via modification of the sea ice-albedo feedback. Mixed-layer ocean has much shallower mixed layer depth than the dynamic ocean in the region of the deep convection in the northern Atlantic. Because of the reduced thermal inertia in the region, mixed-layer ocean model simulates much stronger response of SSTs and sea ice to the external heat forcing than the dynamic ocean model. In the presence of the THC feedback, the sea ice-albedo feedback is much less pronounced. We conclude that the THC feedback to changes in the forest cover is negative.

\subsection{TIME SCALE ANALYSIS: TRANSIENT $\mathrm{CO}_{2}$ EXPERIMENT}

Under a transient increase in the atmospheric $\mathrm{CO}_{2}$ concentration, the trajectory of the climate system in the phase space differs from the equilibrium response. How far, then, from equilibrium is the present state of climate and vegetation in the northern high latitudes? Which component of the climate system sets the dominant time scale at different parts of the system trajectory? To address these questions, we applied to both EMICs a scenario of transient atmospheric $\mathrm{CO}_{2}$ concentrations from a pre-industrial value (280 ppm, year 1800) to twice that value $(560 \mathrm{ppm})$. The scenario (Figure 5a) combines ice core data (Neftel et al., 1990), observations (Keeling, 1993), and results from a simulation of a box model for the global carbon cycle (Svirezhev et al., 1999) driven by the IPCC IS92a emission scenario (Houghton et al., 1992). After the year 2055, when atmospheric $\mathrm{CO}_{2}$ stabilizes at the $560 \mathrm{ppm}$ level, atmospheric $\mathrm{CO}_{2}$ is assumed constant for ca. 2,000 years while the climate-vegetation system relaxes towards a new equilibrium.

Points 1 and 2 are the initial and final equilibrium states from simulations (0) and (C), respectively (Figures 5b,c). Equilibrium manifolds $F^{*}(T), T^{*}(F, 0)$, and $T^{*}(F, C)$ are shown for reference, while transient states of the system, each a 10 -year average, are presented as series of dots. Both EMICs begin with a weak system response through approximately 1970 (slow increase in temperature, nearly constant tree fraction). After 1970 or so, both EMICs go through three clear phases: (i) The system dynamics (shown by arrows in Figure 5b) accelerate with rapid atmospheric but slow vegetation responses to increasing $\mathrm{CO}_{2}$ concentrations. (ii) After the atmospheric $\mathrm{CO}_{2}$ concentration stabilizes, the temperature increase slows 
(a)

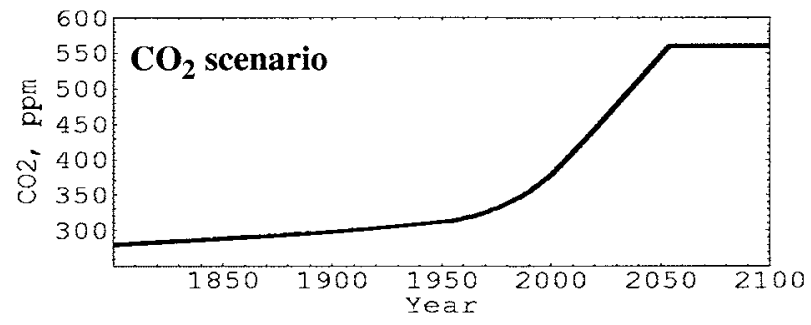

(b)
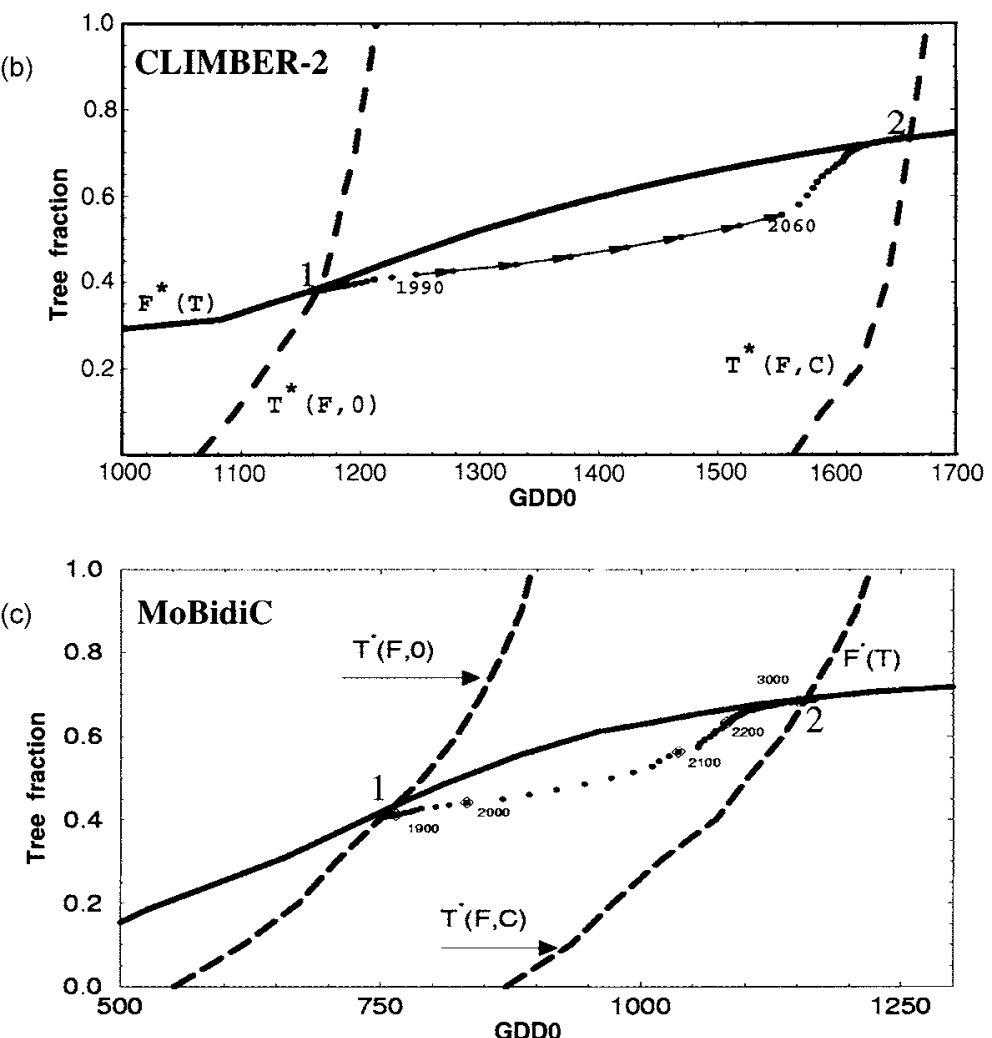

Figure 5. System dynamics under transient $\mathrm{CO}_{2}$ forcing. (a) Transient scenario of atmospheric $\mathrm{CO}_{2}$ concentration. (b) CLIMBER-2, (c) MoBidiC. Points 1 and 2 are the initial and final states, respectively. Dots show decadal averages.

to the response rate of the ocean. In this phase the dynamics are driven mainly by the vegetation response. (iii) Approximately 200 years later, the trajectory meets the $F^{*}(T)$ manifold. From there the system evolves slowly to equilibrium (point 2). This last stage of the trajectory coincides with the $F^{*}(T)$ manifold, suggesting that the vegetation is in quasi-equilibrium with climate. At the thousand-year time scale, then, the system dynamics are determined by the equilibration of the deep ocean with the new land-atmosphere conditions. The assumption that the ocean 
response time considerably exceeds the response time of vegetation is confirmed by an additional transient simulation performed with a mixed-layer MoBidiC configuration (not shown). In this case, the transient trajectory is only characterized by steps (i) and (ii), while step (iii) is absent.

These results point to a significant disequilibrium between the vegetation cover and climate in the northern high latitudes for the present decade. For example, in the CLIMBER-2 simulation the 1990 value of $F(T)$ is lower than the corresponding equilibrium value $F^{*}(T)$ by 0.05 (Figure $5 \mathrm{~b}$ ). This disequilibrium is due to the delayed response of vegetation to climate change. The difference increases up to 0.1 during the first half of the 21 st century due to accelerated warming and despite the rising rate of change in tree fraction, $\Delta F / \Delta t$. The latter increases from about $1 \%$ per decade (1900-2000) to about $2 \%$ per decade (2020-2060). $\Delta F / \Delta t$ doubles near 2020 in the MoBidiC simulation as well (Figure 5c). While small, this change is significant for the sensitive northern environment. Because the change in the tree fraction occurs on a decadal to century time scale, it can be interpreted as rather abrupt in comparison with nearly steady position of the boreal treeline during the last 3,000 yrs (MacDonald et al., 2000).

Increased tree cover, in turn, amplifies the warming in the area, although the strength of the feedback declines as the climate warms. Let us note that a simplified description of vegetation dynamics in the models can lead to overestimation of the rate of the vegetation migration and a greater disequilibrium between climate and vegetation than in our simulations (Solomon and Kirilenko, 1997).

\section{Conclusions}

We investigate the stability of the climate-vegetation system in the northern high latitudes with climate-vegetation models of different complexity: a threedimensional model (GENESIS-IBIS) and two EMICs (CLIMBER-2 and MoBidiC). Results of numerical experiments are interpreted in terms of equilibrium manifolds on a phase plane. A unique steady state is simulated by all the models on a zonal scale for present-day climate and doubled $\mathrm{CO}_{2}$ climate. Decreased insolation experiments with the EMICs also result in a unique equilibrium. In sensitivity experiments with CLIMBER-2, no multiple steady states on a zonal scale are found for intentionally changed parameterizations of snow and forest albedos. However, we cannot rule out the possibility of multiple steady states, for example, due to local scale interactions.

The EMIC simulations show lower climate sensitivity (expressed in degreedays) with higher tree fractions. This is mainly due to a time shift in spring snow melt in response to changes in tree cover. The radiative effect of forests on air temperature is higher in spring than in summer. The higher the tree fraction, the earlier the snow melt, the weaker the radiative effect and the stronger the hydrological 
effect of tree cover. Therefore, the climate sensitivity is higher for low values of tree fraction than for high values of tree fraction.

The GENESIS-IBIS and CLIMBER-2 simulations reveal that the climate sensitivity to changing tree fraction is higher for the present-day than for the doubled $\mathrm{CO}_{2}$ climate. In particular, the warmer climate has a shorter snow season, which leads to a decrease in the significance of the radiative feedback. Simultaneously, as the growing season lengthens, the hydrological feedback increases in importance. In MoBidiC, the hydrological feedback is not simulated, and the difference in $\Delta T_{F}$ between cold and warm climates is less pronounced (Table II).

The EMIC experiments presented in this paper are, to our knowledge, the first simulations exploring the effect of ocean circulation on the climate sensitivity to forest cover in the boreal region (Figure 1). These simulations indicate that the sensitivity is smaller with fixed SSTs and sea ice than with an interactive ocean (CLIMBER-2), which is in turn smaller than with a mixed layer ocean (MoBidiC, see Table II). The mixed layer ocean and interactive sea ice amplify the radiative and hydrological feedbacks which originate on land, while THC feedback dampen the signal.

There is growing observational evidence of recent changes in the northern highlatitude environment including a decline in Arctic sea ice cover, a rise in surface air temperature and photosynthetic activity of plants, and even indicators of a northward trend in the position of the tree line (Serreze et al., 2000). Results of our numerical experiments agree with such observations. EMIC simulations driven with a scenario of transient $\mathrm{CO}_{2}$ reveal that in the 1990s the rate of tree fraction $F$ increase in this region was about $1 \%$ per decade, while the equilibrium tree fraction $F^{*}$ grows at a rate of about $2 \%$ per decade. This points out the significant disequilibrium between present-day climate and vegetation cover in the northern high latitudes, due to a delay in the vegetation's response. Under accelerated $\mathrm{CO}_{2}$ warming, the rate of change in vegetation cover in the following two decades doubles in the models to $2 \%$ per decade. The changes in vegetation cover, in turn, amplify regional warming, although the feedback weakens as the climate warms.

Figure 1 is a simplified cartoon of the complex climate-vegetation interaction in the northern high latitudes. Keeping in mind each model's limitations, it is important to investigate feedbacks with a spectrum of models of different complexity. Every class of models, from greatly simplified conceptual models to high-resolution regional GCMs, plays an important role in this analysis.

\section{Acknowledgements}

The authors thank Paul Higgins and three anonymous reviewers whose comments helped improve the manuscript considerably.

M. Crucifix is a research fellow with the FNRS. This research was partly funded by the Environment Programme of the Commission of the European Communi- 
ties under contract CEE-ENV4-CT95-0130 and the Impulse Programme 'Global Change' (contract GC/DD/13, Belgian State, Prime Minister's Office, Federal Office for Scientific, Technical and Cultural Affairs). The interactive coupling of the MoBidiC with VECODE was done during the visit of V. Brovkin to the Institut d'Astronomie et de Géophysique G. Lemaître. The GENESIS-IBIS simulations were performed at the University of Wisconsin's Climate, People, and Environment Program and at the National Center for Atmospheric Research Climate Simulation Laboratory (NCAR CSL). NCAR is sponsored by the U.S. National Science Foundation.

\section{References}

Baldwin, M. P. and Dunkerton, T. J.: 2001, 'Stratospheric Harbingers of Anomalous Weather Regimes', Science 294, 581-584.

Bergengren, J. C., Thompson, S. L., Pollard, D., and DeConto, R. M.: 2001, 'Modeling Global Climate-Vegetation Interactions in a Doubled $\mathrm{CO}_{2}$ World', Clim. Change 50, 31-75.

Betts, A. K. and Ball, J. H.: 1997, 'Albedo over the Boreal Forest', J. Geophys. Res. 102, 28,901$28,909$.

Betts, R. A.: 1999, 'The Impact of Land Use on the Climate of Present Day', in Ritchie, H. (ed.), Research Activities in Atmospheric and Oceanic Modelling, CAS/JSC WGNE Report No. 28, pp. 7.11-7.12, WMO.

Betts, R. A.: 2000, 'Offset of the Potential Carbon Sink from Boreal Forestation by Decreases in Surface Albedo', Nature 408, 187-190.

Bonan, G. B., Chapin, F. S., III, and Thompson, S. L.: 1995, 'Boreal Forest and Tundra Ecosystems as Components of the Climate System', Clim. Change 29, 145-167.

Bonan, G. B., Pollard, D., and Thompson, S. L.: 1992, 'Effects of Boreal Forest Vegetation on Global Climate', Nature 359, 716-718.

Bogatyrev, B. G.: 1991, 'Model of Transition Processes in the Tundra-Taiga System', Doklady Akademii nauk SSSR 316 (2), 508-511 (in Russian).

Brovkin V., Claussen, M., Petoukhov, V., and Ganopolski, A.: 1998, 'On the Stability of the Atmosphere - Vegetation System in the Sahara/Sahel Region', J. Geophys. Res. 103, 31,61331,624 .

Brovkin, V., Ganopolski, A., Claussen, M., Kubatzki, C., and Petoukhov, V.: 1999, 'Modelling Climate Response to Historical Land Cover Change', Global Ecology and Biogeography 8, 509-517.

Chalita, S. and Le Treut, H., 'The Albedo of Temperate and Boreal Forest and the Northern Hemisphere Climate: A Sensitivity Experiment Using the LMD GCM', Clim. Dyn. 10, 231-240.

Chapin, F. S., III, Bret-Harte, M. S., Hobbie, S. E., Zhong, H. L.: 1996, 'Plant Functional Types as Predictors of Transient Responses of Arctic Vegetation to Global Change', Journal of Vegetation Science 7, 347-358.

Chase, T. N., Pielke, R. A., Kittel, T. G. F., Nemani, R. R., Running, S. W.: 2000, 'Simulated Impacts of Historical Land Cover Changes on Global Climate in Northern Winter, Clim. Dyn. 16, 93-105.

Claussen, M.: 1994, 'On Coupling Global Biome Models with Climate Models', Clim. Res. 4, 203221.

Claussen, M., Brovkin, V., and Ganopolski, A.: 2001, 'Biogeophysical versus Biogeochemical Feedbacks of Large-Scale Land Cover Change', Geophys. Res. Lett. 28, 1011-1014.

Claussen, M. and Gayler, V.: 1997, 'The Greening of Sahara during the Mid-Holocene: Results of an Interactive Atmosphere-Biome Model’, Global Ecol. Biogeog. Lett. 6, 369-377. 
Claussen, M., Mysak, L. A., Weaver, A. J., Crucifix, M., Fichefet, T., Loutre, M.-F., Weber, S. L., Alcamo, J., Alexeev, V. A., Berger, A., Calov, R., Ganopolski, A., Goosse, H., Lohman, G., Lunkeit, F, Mokhov, I.I., Petoukhov, V., Stone, P., Wang, Zh.: 2002, 'Earth System Models of Intermediate Complexity: Closing the Gap in the Spectrum of Climate System Models', Clim. Dyn. 18, 579-586.

Cramer W., Bondeau, A., Woodward, F. I., Prentice, I. C., Betts, R. A., Brovkin, V., Cox, P. M., Fisher, V., Foley, J., Friend, A. D., Kucharik, C., Lomas, M. R., Molling, C., Ramankutty, N., Sitch, S., Smith, B., White, A., Young-Molling, C.: 2001, 'Dynamic Responses of Global Terrestrial Ecosystems to Changes in $\mathrm{CO}_{2}$ and Climate', Global Change Biology 7, 357-373.

Crucifix, M., Loutre, M. F., Tulkens, P., Fichefet, T., and Berger, A.: 2002, 'Climate Evolution during the Holocene: A Study with an Earth System Model of Intermediate Complexity', Clim. Dyn. 19, 43-60.

de Noblet, N. I., Prentice, I. C., Joussaume, S., Texier, D., Botta, A., and Haxeltine, A.: 1996, 'Possible Role of Atmosphere-Biosphere Interactions in Triggering the Last Glaciation', Geophys. Res. Lett. 23, 3191-3194.

Dickinson, R. E., Henderson-Sellers, A., Kennedy, P. J., and Wilson, M. F.: 1986, BiosphereAtmosphere Transfer Scheme (BATS) for the NCAR Community Climate Model, NCAR Technical Note TN-275+STR, Boulder, Colorado, $69 \mathrm{pp}$.

Douville, H. and Royer, J. F.: 1996, 'Influence of the Temperate and Boreal Forests on the Northern Hemisphere Climate in the Meteo-France Climate Model', Clim. Dyn. 13, 57-74.

Foley, J., Kutzbach, J. E., Coe, M. T., and Levis, S.: 1994, 'Feedbacks between Climate and Boreal Forests during the Holocene Epoch', Nature 371, 52-54.

Foley, J. A., Levis, S., Prentice, I. C., Pollard, D., Thompson, S. L.: 1998, 'Coupling Dynamic Models of Climate and Vegetation', Global Change Biology 4, 561-580.

Fosberg, M. A, Cramer, W., Brovkin, V., Fleming, R., Gardner, R., Gill, A. M., Goldammer, J.G., Keane, R., Koehler, P., Lenihan, J., Neilson, R., Sitch, S., Thornicke, K., Venevski, S., Weber, M. G., Wittenberg, U.: 1999, 'Strategy for a Fire Module in Dynamic Global Vegetation Models', Int. J. of Wildland Fire 9, 79-84.

Gallimore, R. G. and Kutzbach, J. E.: 1996, 'Role of Orbitally Induced Changes in Tundra Area in the Onset of Glaciation', Nature 381, 503-505.

Ganopolski, A., Kubatzki, C., Claussen, M., Brovkin, V., and Petoukhov, V.: 1998, 'The Influence of Vegetation-Atmosphere-Ocean Interaction on Climate during the Mid-Holocene', Science 280, 1916-1919.

Ganopolski, A., Petoukhov, V., Rahmstorf, S., Brovkin, V., Claussen, M., Eliseev, A, and Kubatzki, C.: 2001, 'CLIMBER-2: A Climate System Model of Intermediate Complexity. Part II: Validation and Sensitivity Tests', Clim. Dyn. 17, 735-751.

Gaspar P.: 1988, 'Modelling the Seasonal Cycle of the Upper Ocean', J. Phys. Oceanog. 18, 161-180.

Gavrilova, M. K.: 1981, Contemporary Climate and Continental Permafrost, Nauka, Novosibirsk (in Russian).

Harvey, L. D. D.: 1988, 'On the Role of High Latitude Ice, Snow, and Vegetation Feedbacks in the Climatic Response to External Forcing Changes', Clim. Change 13, 191-224.

Heck, P., Luthi, D., Wernli, H., and Schar, C.: 2001, 'Climate Impacts of European-Scale Anthropogenic Vegetation Changes: A Sensitivity Study using a Regional Climate Model', J. Geophys. Res. 106, 7,817-7,835.

Henderson-Sellers, A. and McGuffie, K.: 1995, 'Global Climate Models and "Dynamic" Vegetation Changes', Global Change Biology 1, 63-75.

Hewitt, C. D. and Mitchell, J. F. B.: 1998, 'A Fully Coupled GCM Simulation of the Climate of the Mid-Holocene', Geophys. Res. Lett. 25, 361-364.

Houghton, J. T., Callander, B. A., and Varney, S. K. (eds.): 1992, Climate Change 1992: Supplementary Report to the IPCC Scientific Assessment, Cambridge Univ. Press, New York. 
Keeling, C. D.: 1993, Atmospheric $\mathrm{CO}_{2}$ Concentrations - Mauna Loa Observatory, Hawaii, 19581993, NDP-001, CDIAC, ORNL, Oak Ridge.

Kleidon, A., Fraedrich, K., and Heimann, M.: 2000, 'A Green Planet versus a Desert World: Estimating the Maximum Effect of Vegetation on the Land Surface Climate', Clim. Change 44, 471-493.

Kubatzki, C. and Claussen, M.: 1998, 'Simulation of the Global Biogeophysical Interactions during the Last Glacial Maximum', Clim. Dyn. 14, 461-471.

Kubatzki, C., Montoya, M., Rahmstorf, S., Ganopolski, A., and Claussen, M.: 2000, 'Comparison of the Last Interglacial Climate Simulated by a Coupled Global Model of Intermediate Complexity and an AOGCM', Clim. Dyn. 16, 799-814.

Levis, S., Foley, J. A., Brovkin, V., and Pollard, D.: 1999a, 'On the Stability of the High-Latitude Climate-Vegetation System in a Coupled Atmosphere-Biosphere Model', Global Ecol. and Biogeography 8, 489-500.

Levis, S., Foley, J. A., and Pollard, D.: 1999b, ' $\mathrm{CO}_{2}$, Climate and Vegetation Feedbacks at the Last Glacial Maximum', J. Geophys. Res. 104, 31,191-31,198.

Levis, S., Foley, J. A., and Pollard, D.: 1999c, 'Potential High-Latitude Vegetation Feedbacks on $\mathrm{CO}_{2}$-Induced Climate Change', Geophys. Res. Lett. 26, 747-750.

MacDonald, G. M., Kremenetski, C. V., Velichko, A. A., Cwynar, L. C., Riding, R. T., Goleva, A. A., Andreev, A. A., Borisova, O. K., Edwards, T. W. D., Hammarlund, D., Szeicz, J. M., Forman, S., Gataullin, V. I.: 2000, 'Eurasian Treeline Change Linked to the North Atlantic', Quartern. Res. 53, 302-311.

McGuffie, K. and Henderson-Sellers, A., 2001, 'Forty Years of Numerical Climate Modelling', Int. J. Climatol. 21, 1067-1109.

Neftel, A., Moor, E., Oeschger, H., Stauffer, B., Friedli, H., Lütscher, H., and Siegenthaler, U.: 1990, 'Atmospheric Carbon Dioxide Concentration - Historical Record, Siple Station', Trends 90: A Compendium of Data on Global Change, Report 36, CDIAC, ORNL, Oak Ridge.

Ni, W. and Woodcock, C. E.: 2000, 'Effect of Canopy Structure and the Presence of Snow on the Albedo of Boreal Conifer Forests', J. Geophys. Res. 105, 11,879-11,888.

Otterman, J., Chou, M. D., and Arking, A.: 1984, 'Effects of Nontropical Forest Cover on Climate', J. Clim. Appl. Meteorol. 23, 762-767.

Petoukhov, V., Ganopolski, A., Brovkin, V., Claussen, M., Eliseev, A., Kubatzki, C., Rahmstorf, S.: 2000, 'CLIMBER-2: A Climate System Model of Intermediate Complexity', Clim. Dyn. 16, $1-17$.

Pielke, R. A., Avissar, R., Raupach, M., Dolman, A. J., Zeng, X., and Denning, A. S.: 1998, 'Interaction, between the Atmosphere and Terrestrial Ecosystems: Influence on Weather and Climate', Global Change Biology 4, 461-475.

Pielke, R. A. and Vidale, P. L.: 1995, 'The Boreal Forest and the Polar Front', J. Geophys. Res. 100, $25,755-25,758$.

Prentice, I. C., Cramer, W., Harrison, S. P., Leemans, R., Monserud, R. A., and Solomon, A. M.: 1992, 'A Global Biome Model Based on Plant Physiology and Dominance, Soil Properties and Climate', J. Biogeogr. 19, 35-57.

Rahmstorf, S., Marotzke, J., and Willebrand, J.: 1996, 'Stability of the Thermohaline Circulation', in Krauss, W. (ed.), The warm water sphere of the North Atlantic ocean, Borntraeger, Stuttgart, pp. $129-158$.

Scheffer, M., Carpenter, S., Foley, J., Folke, S., and Walker, B.: 2001, 'Catastrophic Shifts in Ecosystems', Nature 413, 591-596.

Schlesinger, M.: 1985, 'Feedback Analysis of Results from Energy Balance and Radiative- Convective Models', in MackCracen, M. C. and Luther, F. M. (eds.), The Potential Climatic Effects of Increasing Carbon Dioxide, U. S. Departament of Energy, DOE/ER-0237, pp. 280-319. 
Serreze, M. C., Walsh, J. E., Chapin, F. S., Osterkamp, T., Dyurgerov, M., Romanovsky, V., Oechel, W. C., Morison, J., Zhang T., and Barry, R. G.: 2000, 'Observational Evidence of Recent Change in the Northern High-Latitude Environment', Clim. Change 46, 159-207.

Solomon, A. M. and Kirilenko, A. P.: 1997, 'Climate Change and Terrestrial Biomass: What if Trees do not Migrate!', Global Ecology and Biogeography Letters 6, 139-148.

Stein, U. and Alpert, P.: 1993, 'Factor Separation in Numerical Simulations', J. Atmos. Sci. 50, 2107-2115.

Svirezhev, Yu., Brovkin, V., von Bloh, W., Schellnhuber, H.-J., and Petschel-Held, J.: 1999, 'Optimization of Global $\mathrm{CO}_{2}$ Emission Based on a Simple Model of the Carbon Cycle', Environ. Model. Assess. 4, 23-33.

Svirezhev, Y. and von Bloh, W.: 1996, 'A Minimal Model of Interaction between Climate and Vegetation: Qualitative Approach', Ecol. Modelling 92, 89-99.

Texier, D., de Noblet, N., Harrison, P. S., Haxeltine, A., Jolly, D., Joussaume, S., Laarif, F., Prentice, I. C., and Tarasov, P.: 1997, 'Quantifying the Role of Biosphere-Atmosphere Feedbacks in Climate Change: Coupled Model Simulations for 6000 Years BP and Comparison with Palaeodata for Northern Eurasia and Africa', Clim. Dyn. 13, 865-882.

Thomas, G. and Rowntree, P. R.: 1992, 'The Boreal Forest and Climate', Quart J. Roy. Meteorol. Soc. 118, 469-497.

Thompson, S. L. and Pollard, D.: 1997, 'Greenland and Antarctic Mass Balances for Present and Doubled Atmospheric $\mathrm{CO}_{2}$ from the GENESIS Version 2 Global Climate Model, J. Climate 10, 871-900.

Tyrtikov, A. P.: 1995, Forest on the Northern Limit in Asia, KMK Scientific Press Ltd., Moscow, 146 pp. (In Russian with English summary).

Woodward, F. I.: 1987, Climate and Plant Distribution, Cambridge Univ. Press, New York, 174 pp.

(Received 20 November 2000; in revised form 27 June 2002) 